\title{
Clinical trials in rare diseases: a review of practice
}

\author{
Stuart Bell ${ }^{1}$, Paula Williamson ${ }^{1}$, Simon Day ${ }^{2}$, Keith Wheatley ${ }^{4}$, John Whitehead ${ }^{3}$, Catrin Tudur Smith ${ }^{{ }^{*}}$ \\ From 2nd Clinical Trials Methodology Conference: Methodology Matters \\ Edinburgh, UK. 18-19 November 2013
}

\section{Background}

The evaluation of treatments for rare diseases presents a number of challenges for trial practitioners, regulators and policy makers. Small sample sizes mean that 'standard' approaches to trial design and analysis may not be appropriate and alternatives such as Bayesian trial designs have been recommended [Lilford et al 1995]. However, little is known about the design and analysis approaches that have been implemented in practice.

\section{Methods}

We will perform a review of rare disease clinical trials to

(i) describe the trial design characteristics that have been applied to rare disease clinical trials;

(ii) summarise the characteristics that facilitate or hinder the design, conduct and publication of rare disease clinical trials;

(iii) summarise approaches in which researchers have attempted to improve the efficiency of rare disease clinical trials;

(iv) identify whether alternative design and analysis considerations may have been possible in a given trial.

Rare disease clinical trials will be identified through electronic search of trial registries (http://www.clinicaltrials. gov and http://www.orpha.net). Trials will be assessed for inclusion by two independent reviewers and relevant data extracted. Trials will be summarised qualitatively with regard to the methodologies adopted and their strengths and weaknesses.

\section{Results}

Preliminary results will be available to discuss at the conference.

\section{Conclusions}

The purpose of this review is to explore how rare disease trials have been implemented. This will provide a

${ }^{1}$ University of Liverpool, Liverpool, UK

Full list of author information is available at the end of the article much needed summary of approaches that have been used in practice, highlighting where possible, why particular designs have been chosen.

\section{Authors' details}

'University of Liverpool, Liverpool, UK. ${ }^{2}$ Roche Products Limited, Welwyn Garden City, UK. ${ }^{3}$ Lancaster University, Lancaster, UK. ${ }^{4}$ Birmingham University, Birmingham, UK.

Published: 29 November 2013

doi:10.1186/1745-6215-14-S1-P34

Cite this article as: Bell et al: Clinical trials in rare diseases: a review of practice. Trials 2013 14(Suppl 1):P34.

Submit your next manuscript to BioMed Central and take full advantage of:

- Convenient online submission

- Thorough peer review

- No space constraints or color figure charges

- Immediate publication on acceptance

- Inclusion in PubMed, CAS, Scopus and Google Scholar

- Research which is freely available for redistribution 